Original article

\title{
Design and in vitro/in vivo evaluation of extended release matrix tablets of nateglinide
}

\author{
Pushkar R. Sharma, Shaila A. Lewis* \\ Department of Pharmaceutics, Manipal College of Pharmaceutical Sciences, Manipal University, Manipal 576 104, Karnataka, India
}

\section{A R T I C L E I N F O}

\section{Article history:}

Received 13 July 2013

Accepted 16 November 2013

Available online 11 December 2013

\section{Keywords:}

Hydroxypropylmethylcellulose

Matrix tablets

Nateglinide

Sustained release

\begin{abstract}
A B S T R A C T
Aim: Nateglinide is a quick acting anti-diabetic medication whose potent activity lasts for a short duration. One of the dangerous side effects of nateglinide administration is rapid hypoglycemia, a condition that needs to be monitored carefully to prevent unnecessary fatalities. The aim of the study was to develop a longer lasting and slower releasing formulation of nateglinide that could be administered just once daily.

Methods: Matrix tablets of nateglinide were prepared in combination with the polymers hydroxypropylmethylcellulose (HPMC), eudragits, ethyl cellulose and polyethylene oxide and the formulated drug release patterns were evaluated using in vitro and in vivo studies.

Conclusion: Of the seventeen formulated matrix tablets tested, only one formulation labelled HA-2 that contained 15\% HPMC K4M demonstrated release profile we had aimed for. Further, swelling studies and scanning electron microscopic analysis confirmed the drug release mechanism of HA-2. The optimized formulation HA-2 was found to be stable at accelerated storage conditions for 3 months with respect to drug content and physical appearance. Mathematical analysis of the release kinetics of HA-2 indicated a coupling of diffusion and erosion mechanisms. In-vitro release studies and pharmacokinetic in vivo studies of HA-2 in rabbits confirmed the sustained drug release profile we had aimed for.

Copyright (c) 2013, InPharm Association, Published by Reed Elsevier India Pvt. Ltd. All rights reserved.
\end{abstract}

\section{Introduction}

Nateglinide, a D-phenylalanine derivative is an anti-diabetic drug that is quick but short acting and controls postprandial blood glucose (PBG) effectively. Nateglinide belongs to the meglitinide class of anti-diabetic drugs used to treat type 2 diabetes by stimulation of pancreatic beta cells that results in the release of proinsulin. Nateglinide immediate-release tablets are administered twice or thrice a day. ${ }^{1,2}$ A sustained release formulation of nateglinide would enable control of both PBG and FBG (fasting blood glucose) with the novel advantage of improving patient compliance by decreasing multiple drug administration and minimizing side effects such as hypoglycemia and hepatic impairment. ${ }^{3,4}$ The usual dose of nateglinide administered is three times a day. By using a higher 24-hr dose of nateglinide in a single matrix tablet, the drug is released at a slower rate thus preventing extremely high and low concentrations of nateglinide in plasma. This helps to avoid the side effects of hypoglycemia and hepatic impairment associated with high concentration and the lack of drug activity when its concentration in plasma is low. A slower release formulation would

\footnotetext{
* Corresponding author. Tel.: +91 82029224842.

E-mail address: s.lewis@manipal.edu (S.A. Lewis).
}

therefore enhance the therapeutic effects of nateglinide. Oral drug delivery system is the most accepted route for drug delivery, its benefits being easy administration and flexibility in dosage form design. ${ }^{5}$ There are several approaches for retarding drug release from dosage form. ${ }^{6}$ Matrix tablets composed of drug and release retarding polymers offer the simplest approach in designing a sustained release system. ${ }^{7}$ The goals of the present study were to develop a once-daily sustained-release dosage form of nateglinide in tablet form using different polymers in varying proportions and to determine which combination best fit the desired release profile. The prepared tablets were evaluated with respect to physicochemical parameters including in-vitro drug release, stability, surface morphology and in vivo pharmacokinetics in rabbits.

\section{Experimental materials}

Nateglinide, hydroxypropylmethylcellulose (K4M, K15M and $\mathrm{K} 100 \mathrm{M}$ ) and polyethylene oxide N80F were obtained from Lupin Laboratories Ltd, Pune, India. Eudragit RS 100 and Eudragit RL 100 were obtained from Vikram Thermolab Ahmedabad, India. Magnesium stearate, talc, lactose, hydrochloric acid and methanol, were purchased from S.D. Fine-Chem Limited, Merck, Loba Chemie Mumbai, India respectively. All other chemicals used were of analytical grade. 


\section{Experimental methods}

\subsection{Preparation of nateglinide tablets}

Tablets were prepared by direct compression. The investigated formulations are shown in Table 1. The respective powders (drug, polymers and excipients) were passed through 60\# sieve. The powders were blended thoroughly using a mortar and pestle after which $500 \mathrm{mg}$ of each mixture were weighed and manually fed into the die of a single punch tableting machine (Rimix tableting machine, Gujarat, India) equipped with $10.5 \mathrm{~mm}$ flat punches.

\subsubsection{Conventional tablets for rabbits}

Doses for rabbits were calculated using following formula of Gosh. ${ }^{8,9}$ According to the dose calculated for rabbits $(48.30 \mathrm{mg}$ ), the same formula was proportionately reduced and compressed into tablets using $2.5 \mathrm{~mm}$ flat punch.

Rabbit dose $=0.07 \times$ human dose

where, human dose $=345 \mathrm{mg}$, rabbit weight $=2 \mathrm{~kg}$ and rabbit dose $=48.300 \mathrm{mg}$. The rabbit dose was found to be 1.5 times the observed value.

\subsection{Evaluation of prepared tablets}

\subsubsection{Thickness and diameter}

The prepared matrix tablets were evaluated for thickness, hardness, friability and drug content. Thicknesses of randomly selected tablets were determined using screw gauge. Hardness of the tablets was determined using Monsanto Hardness tester. Friability of tablets was determined using Roche Friabilator according to the official method IP. ${ }^{10}$ The values are expressed as the mean of three measurements $( \pm \mathrm{SD})$.

\subsubsection{Drug content}

For determination of drug content, tablets were crushed and $100 \mathrm{mg}$ of powder was dissolved in $100 \mathrm{ml}$ of methanol. The filtrate further diluted with phosphate buffer ( $\mathrm{pH}$ 6.8) was analyzed spectrophotometrically (UV-1601PC, Shimadzu, Japan) at $210 \mathrm{~nm}$. Drug content was calculated using a standard curve generated using various concentrations of nateglinide in phosphate buffer ( $\mathrm{pH} 6.8$ ).

\subsubsection{In vitro dissolution study}

An in-vitro dissolution study of formulated matrix tablets was carried out in $900 \mathrm{ml} 0.5 \%$ sodium lauryl sulphate (SLS) in $0.01 \mathrm{~N}$ $\mathrm{HCl}$, followed by $900 \mathrm{ml}$ of Phosphate buffer (pH 6.8) with type II paddle dissolution apparatus (Electrolab, TDL-08L, Mumbai, India) run at $50 \mathrm{rpm}$. The temperature of the medium was maintained at $37 \pm 0.5{ }^{\circ} \mathrm{C}$. Samples $(5 \mathrm{ml})$ were withdrawn at predetermined intervals and read at $210 \mathrm{~nm}$ using a spectrophotometer.

\subsubsection{Determination of swelling:eroding behaviour}

The swelling-eroding behaviour of matrix tablets was determined using the method described by Al-Taani and Tashoush. ${ }^{11}$ One matrix tablet was weighed and placed in a dissolution apparatus. The swollen weights of tablets were calculated after placing the mixture in a vacuum oven at $40{ }^{\circ} \mathrm{C}$ for $48 \mathrm{~h}$. The following formula was used for calculating \% swelling

$\%$ Swelling $=S / R \times 100$

where, $S$ is the weight of the matrix after swelling and $R$ is the weight of the eroded matrix.

$\%$ Erosion $=T-R / T \times 100 \%$

where, $R$ is the weight of the eroded matrix and $T$ is the initial weight of the matrix.

\subsubsection{Scanning electron microscopy}

A SEM study of the optimized formulation was carried out confirming drug release mechanism. SEM photograph of the matrix tablets were taken at $0 \mathrm{~h}, 2 \mathrm{~h}, 12 \mathrm{~h}$ and $24 \mathrm{~h}$ of dissolution.

\subsubsection{Stability}

The tablets were kept under accelerated storage conditions $40 \pm 2{ }^{\circ} \mathrm{C}$ and $75 \pm 5 \%$ relative humidity according to ICH guidelines using a stability chamber (Thermolab, Mumbai) for a period of three months. The samples were withdrawn at predetermined time intervals and evaluated for drug content and physical parameters.

\subsubsection{In vivo pharmacokinetic study}

An in vivo pharmacokinetic study was conducted in accordance with the ethical guidelines for investigations in laboratory animals and approved by the Institutional Animal Ethics Committee (IAEC), Manipal University (MU) No.IAEC/KMC/21/2011. All procedures and care of the rabbits were in accordance with institutional guidelines for animal use in research. Twelve Rabbits (New Zealand, White) weighing $2.30 \pm 0.12 \mathrm{~kg}$ (divided into two groups) were fasted overnight. Tablets were administered orally via gastric intubation. The first group received conventional tablet while the second group received optimized extended release tablet of nateglinide. Rabbits were held in rabbit restainers during blood sampling. Blood samples were collected from ear veins at predetermined intervals of

Table 1

Formulation of different batches of matrix tablets.

\begin{tabular}{|c|c|c|c|c|c|c|c|c|c|c|c|c|c|c|c|c|c|}
\hline \multirow[t]{2}{*}{ Ingredients (mg/tablet) } & \multicolumn{17}{|c|}{ Batch code } \\
\hline & HA-1 & HA-2 & HA-3 & HB-1 & HB-2 & HB-3 & HC-1 & $\mathrm{EC}-1$ & ES-1 & ES-2 & ES-3 & EL-1 & EL-2 & EL-3 & PO-1 & PO-2 & $\mathrm{PO}-3$ \\
\hline Nateglinide & 345 & 345 & 345 & 345 & 345 & 345 & 345 & 345 & 345 & 345 & 345 & 345 & 345 & 345 & 345 & 345 & 345 \\
\hline Lactose & 45 & 70 & 95 & 45 & 70 & 95 & 45 & 45 & 45 & 70 & 95 & 45 & 70 & 95 & 45 & 70 & 95 \\
\hline HPMC K4M & 100 & 75 & 50 & $* *$ & $* *$ & $* *$ & $* *$ & $* *$ & $* *$ & $* *$ & $* *$ & $* *$ & $* *$ & $* *$ & $* *$ & $* *$ & $* *$ \\
\hline HPMC K15M & $* *$ & $* *$ & $* *$ & 100 & 75 & 50 & $* *$ & $* *$ & $* *$ & $* *$ & $* *$ & $* *$ & $* *$ & $* *$ & $* *$ & $* *$ & $* *$ \\
\hline HPMC К100M & $* *$ & $* *$ & $* *$ & $* *$ & $* *$ & $* *$ & 100 & $* *$ & $* *$ & $* *$ & $* *$ & $* *$ & $* *$ & $* *$ & $* *$ & $* *$ & $* *$ \\
\hline Ethyl Cellulose & $* *$ & $* *$ & $* *$ & $* *$ & $* *$ & $* *$ & $* *$ & 100 & $* *$ & $* *$ & $* *$ & $* *$ & $* *$ & $* *$ & $* *$ & $* *$ & $* *$ \\
\hline Eudragit RS-100 & $* *$ & $* *$ & $* *$ & $* *$ & $* *$ & $* *$ & $* *$ & $* *$ & 100 & 75 & 50 & $* *$ & $* *$ & $* *$ & $* *$ & $* *$ & $* *$ \\
\hline Eudragit RL-100 & $* *$ & $* *$ & $* *$ & $* *$ & $* *$ & $* *$ & $* *$ & $* *$ & ** & $* *$ & $* *$ & 100 & 75 & 50 & $* *$ & $* *$ & $* *$ \\
\hline Polyethylene oxide N $80 \mathrm{~F}$ & $* *$ & $* *$ & $* *$ & $* *$ & $* *$ & $* *$ & $* *$ & $* *$ & $* *$ & $* *$ & $* *$ & $* *$ & $* *$ & $* *$ & 100 & 75 & 50 \\
\hline Talc & 5 & 5 & 5 & 5 & 5 & 5 & 5 & 5 & 5 & 5 & 5 & 5 & 5 & 5 & 5 & 5 & 5 \\
\hline Mag. Stearate & 5 & 5 & 5 & 5 & 5 & 5 & 5 & 5 & 5 & 5 & 5 & 5 & 5 & 5 & 5 & 5 & 5 \\
\hline Total Tab. Wt. & 500 & 500 & 500 & 500 & 500 & 500 & 500 & 500 & 500 & 500 & 500 & 500 & 500 & 500 & 500 & 500 & 500 \\
\hline
\end{tabular}

** Indicates that ingredient is not included. 
$0.5,1,2,4,8,12$ and 24 h post dose into heparinized tubes. ${ }^{12}$ Plasma samples were obtained following centrifugation of blood at $3500 \times \mathrm{g}$ for $5 \mathrm{~min}$ at $4{ }^{\circ} \mathrm{C}$ and kept frozen at $-70^{\circ} \mathrm{C}$ until analysis.

\subsubsection{Analysis of plasma nateglinide concentration using HPLC ${ }^{13}$}

A sensitive HPLC (HPLC-LC-2010C HT, Shimadzu, Japan) method was used for the estimation of nateglinide in plasma. The mobile phase consisted of acetonitrile and phosphate buffer ( $\mathrm{pH} 3$ ) 50:50 $\mathrm{v} / \mathrm{v}$. The column was $\mathrm{C} 18(250 \mathrm{~cm} \times 4.6 \mathrm{~mm})$ Hypersil BDS, The mobile phase was delivered at a flow rate of $1.0 \mathrm{ml} / \mathrm{min}$, the detection wavelength was $210 \mathrm{~nm}$. All assays were performed at ambient temperature.

\subsubsection{Preparation of sample solutions}

Rabbit plasma (100 $\mu \mathrm{l})$ were pipetted into centrifugal tubes, $10 \mu \mathrm{l}$ of IS (gliclazide) $500 \mu \mathrm{gmL}^{-1}$ was added and vortexed for $10 \mathrm{~s}$. Then $100 \mu \mathrm{l}$ methanol and acetonitrile $100 \mu \mathrm{l}$ were added and vortexed for $30 \mathrm{~s}$ and centrifuged at $10000 \mathrm{rpm}$ for $10 \mathrm{~min}$ at $4{ }^{\circ} \mathrm{C}$. The supernatant layer $(200 \mu \mathrm{l})$ was separated out, $100 \mu \mathrm{l}$ of mobile phase was added to make up the volume to $300 \mu \mathrm{l}$ and then $50 \mu \mathrm{l}$ was injected into HPLC system.

Pharmacokinetic analysis was performed by means of noncompartmental pharmacokinetic data analysis software PK Solutions 2.0 TM.

\section{Results}

\subsection{Evaluation of prepared tablets}

The tablets exhibited uniform thickness and hardness. The friability and drug content were also within the acceptable limits.

\subsection{In vitro release profile}

Release parameters of the tablet formulations are summarized in Fig. 1. Nateglinide release from the prepared tablets was slow, spanning a period of $24 \mathrm{~h}$ and rested on the grade of the controlled release polymer. The results of dissolution studies indicated that HA-1, ES-1, EL-1, EC-1 and PO-1 released 7.31, 2.27, 0.50, 0.99 and $3.93 \%$ of nateglinide at the end of $0.5 \mathrm{~h}$; at $24 \mathrm{~h}, 91.14,78.22,77.45$, 60.40 and $78.43 \%$ of nateglinide was released. Since formulation EC-I containing ethyl cellulose showed incomplete release in the $24 \mathrm{~h}$, further studies were discontinued.

A study was undertaken to determine the release profile of nateglinide matrix tablets with different viscosity grades of HPMC and thereby select a suitable polymer. HPMC K15M and HPMC $\mathrm{K} 100 \mathrm{M}$ were selected for formulation and their release profile compared with HPMC K4M matrix tablets. Results indicate that the

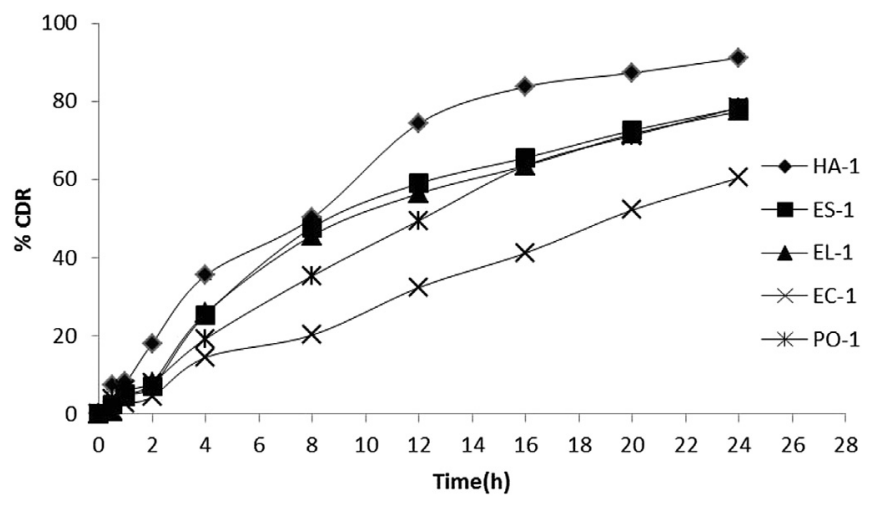

Fig. 1. Release profile of formulations containing different polymers.
Table 2

Release data of formulations.

\begin{tabular}{lcl}
\hline Formulation & \% Release at $0.5 \mathrm{~h}$ & \% Release at $24 \mathrm{~h}$ \\
\hline HA-1 & $7.31 \pm 1.23$ & $91.14 \pm 1.98$ \\
$\mathrm{HB}-1$ & $3.39 \pm 1.67$ & $85.28 \pm 2.56$ \\
$\mathrm{HC}-1$ & $1.02 \pm 3.12$ & $64.75 \pm 3.67$ \\
$\mathrm{HA}-2$ & $9.35 \pm 5.23$ & $96.62 \pm 4.10$ \\
$\mathrm{HA}-3$ & $10.72 \pm 0.89$ & $97.92 \pm 2.78$ \\
$\mathrm{HB}-2$ & $5.00 \pm 4.12$ & $94.44 \pm 2.67$ \\
$\mathrm{HB}-3$ & $7.14 \pm 3.90$ & $96.12 \pm 1.78$ \\
ES-1 & $2.27 \pm 1.56$ & $78.22 \pm 2.13$ \\
ES-2 & $4.24 \pm 2.67$ & $90.39 \pm 2.94$ \\
ES-3 & $4.99 \pm 4.24$ & $97.06 \pm 3.45$ \\
EL-1 & $0.50 \pm 0.98$ & $77.45 \pm 1.45$ \\
EL-2 & $2.53 \pm 1.56$ & $92.53 \pm 2.15$ \\
EL-3 & $2.77 \pm 3.12$ & $94.34 \pm 4.67$ \\
PO-1 & $3.93 \pm 0.98$ & $78.43 \pm 3.44$ \\
PO-2 & $6.32 \pm 1.67$ & $82.39 \pm 3.14$ \\
PO-3 & $7.56 \pm 2.13$ & $90.30 \pm 3.23$
\end{tabular}

All values are expressed as Mean \pm SE, $n=3$. HA-1 (HPMC K4M 20\%), HA-2(HPMC K4M 15\%), HA-3(HPMC K4M 10\%). HB-1 (HPMC K15M 20\%) HB-2(HPMC K15M 15\%) HB-3 (HPMC K15M 10\%). HC-1 (HPMC K100M 20\%) ES-1-(Eudragit RS-100 20\%), ES2-(Eudragit RS-100 15\%), ES-3-(Eudragit RS-100 10\%). EL-1-(Eudragit RL-100 20\%), EL-2-(Eudragit RL-100 15\%), EL-3-(Eudragit RL-100 10\%). PO-1 (polyethylene oxide $20 \%$ ), PO-2 (polyethylene oxide 15\%), PO-3 (polyethylene oxide 10\%).

tablet formulations HA-1(HPMC K4M), HB-1(HPMC K15M) and HC1 (HPMC K100M) released 7.31, 3.39 and $1.02 \%$ at the end of $0.5 \mathrm{~h}$ and $91.14 \%, 85.28 \%$ and $64.75 \%$ of nateglinide at the end of $24 \mathrm{~h}$. The release profile of $\mathrm{HC}-1$ was retarded when compared to the formulations HA-1 and HB-1. Hence HA-I and HB-2 were selected for the further studies.

In formulations HA-1, HA-2 and HA-3 containing 20\%, 15\% and 10\% HPMC K4M respectively, the percentage release was 7.31, 9.35 and $10.72 \%$ respectively at the end of $0.5 \mathrm{~h}$ and $91.14,96.62$ and $97.92 \%$ at the end of $24 \mathrm{~h}$. In the cases of formulations HB-1, HB-2 and HB-3 containing 20\%, 15\% and 10\% HPMC K15M respectively, the percentage releases were $3.93,5.00$ and $7.14 \%$ respectively at the end of $0.5 \mathrm{~h}$ and $85.28,94.44$ and $96.12 \%$ at the end of $24 \mathrm{~h}$. Release studies illustrate incomplete drug release with formulation HA-1 and with formulation HA-3 it was observed that tablet integrity was lost resulting in complete release within $12 \mathrm{~h}$.

Since release of nateglinide with $15 \%$ of HPMC K15M and $10 \%$ of HPMC K15M were lower compared with same concentrations of HPMC K4M, formulation HA-2 was selected for further studies.

For formulations ES-1, ES-2 and ES-3 containing 20\%, 15\% and $10 \%$ Eudragit RS-100, the percentage releases were $2.27,4.24$ and $4.99 \%$ respectively at the end of $0.5 \mathrm{~h}$ and $78.22,90.39$ and $97.06 \%$ at the end of $24 \mathrm{~h}$ (Table 2). For formulations EL-1, EL-2 and EL-3

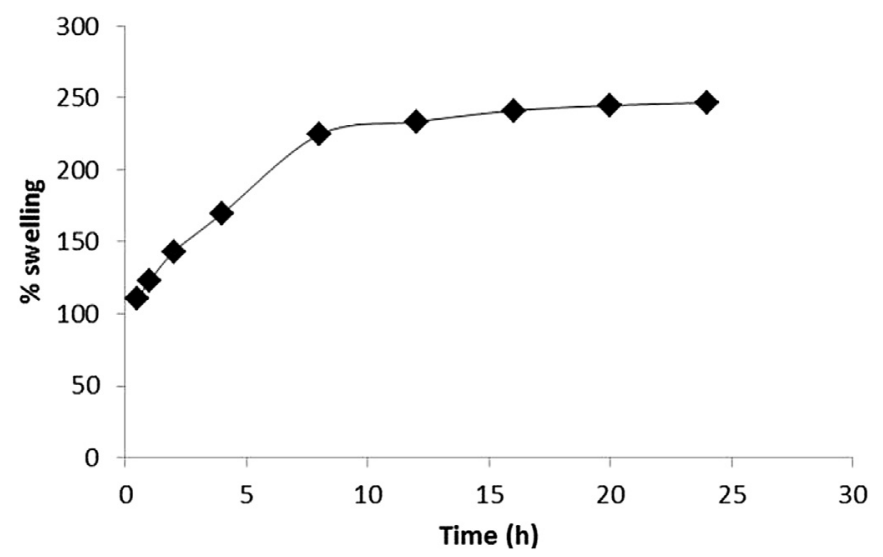

Fig. 2. Percentage swelling of optimized formulation HA-2. 


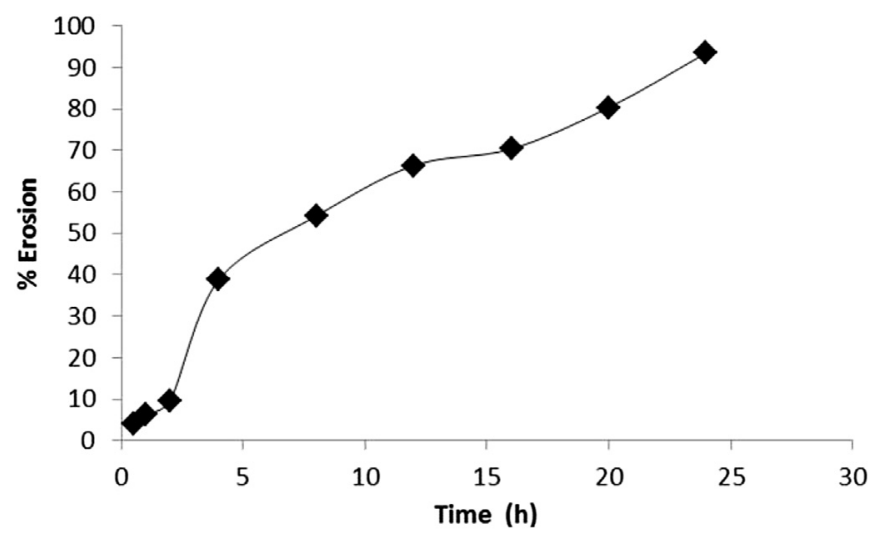

Fig. 3. Percentage erosion of optimized formulation HA-2.

which contain $20 \%, 15 \%$ and $10 \%$ Eudragit RL 100, the percentage releases were $0.50,2.53$ and 2.77 respectively at the end of $0.5 \mathrm{~h}$ and $77.45,92.53$ and $94.34 \%$ at the end of $24 \mathrm{~h}$ (Table 2). These results indicate that lower percentage of Eudragit exhibit satisfactory release over a period of $24 \mathrm{~h}$. Eudragits were not considered for further studies since inadequate amount of nateglinide was released at $0.5 \mathrm{~h}$.

Matrix tablets with the polymer polyethylene oxide, PO-1, PO-2 and $\mathrm{PO}-3$, exhibited better release with reduction in polymer concentration. Percentage release found with $20 \%, 15 \%$ and $10 \%$ polyoxyethylene were $78.43 \%, 82.39 \%$, and $90.30 \%$ respectively; also, $10 \%$ polymer showed an initial release of $7.56 \%$ in $0.5 \mathrm{~h}$ (Table 2) .The results indicate that $10 \%$ polyoxyethylene has potential for extended release formulation and further trials are needed to assess this potential. Formulation HA-2 (15\% HPMC K4M) was selected for further studies.
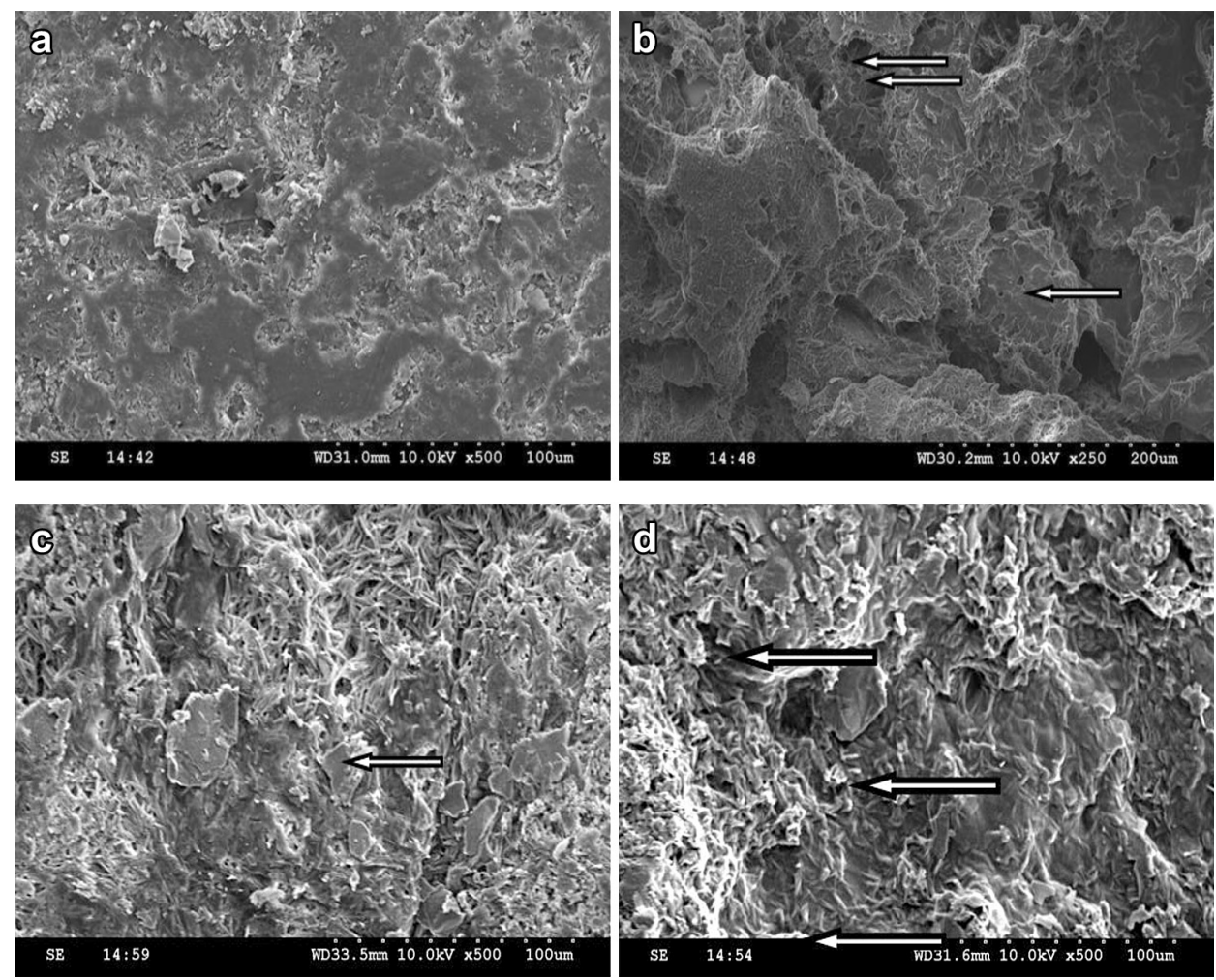

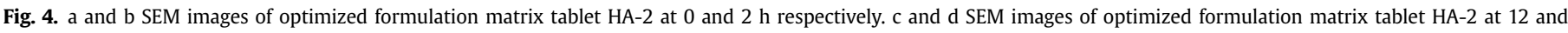
24 h respectively.
Figs. 2 and 3 represent the percentage swelling and percentage matrix erosion respectively as a function of time. The matrix tablets underwent both swelling and erosion at the same time after placement in the dissolution media. SEM study of the optimized formulation taken at $0 \mathrm{~h}, 2 \mathrm{~h}, 12 \mathrm{~h}$ and $24 \mathrm{~h}$ of dissolution are shown in Fig. 4.

\subsection{In vivo pharmacokinetic study}

The retention time of nateglinide and gliclazide was 11.5 and 7.55 min respectively (Fig. 5). The plasma concentrations of conventional nateglinide and extended release formulation over time are presented in Figs. 6 and 7 respectively. The pharmacokinetic parameters of conventional nateglinide and extended release formulation are presented in Table 3.

\subsection{Stability studies}

Accelerated stability studies conducted for the optimized batch of nateglinide extended release matrix tablets (HA-2) showed no change in drug appearance and assay after storage at $40{ }^{\circ} \mathrm{C}$ for 3 months. The drug content was $97 \%$ at the end of 90 days and appearance was unchanged indicating that the optimized formulation is fairly stable at accelerated storage condition.

\section{Discussion}

The results of dissolution studies indicate that release was influenced by the grade of control release polymer. Polymers ethyl cellulose, HPMC K100M, eudragits and polyethylene oxide had a retarding effect compared to polymers HPMC K4M and HPMC $\mathrm{K} 15 \mathrm{M}$ when used in same concentration. Hence further trials were not undertaken with these polymers. When polymer concentration 


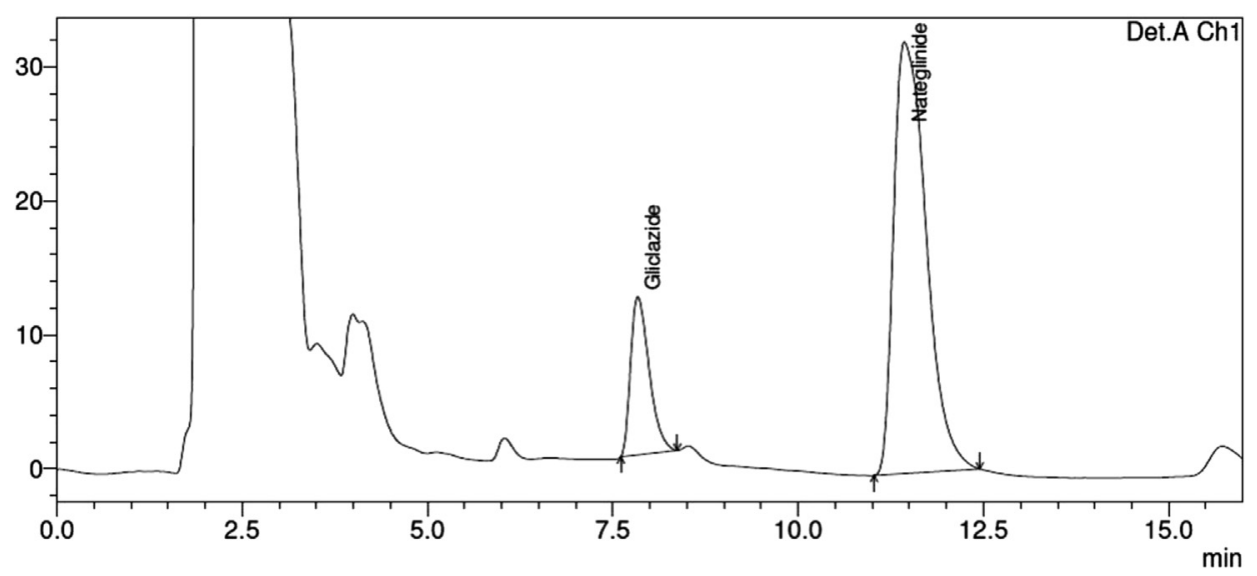

Fig. 5. Retention time of nateglinide and internal standard gliclazide.

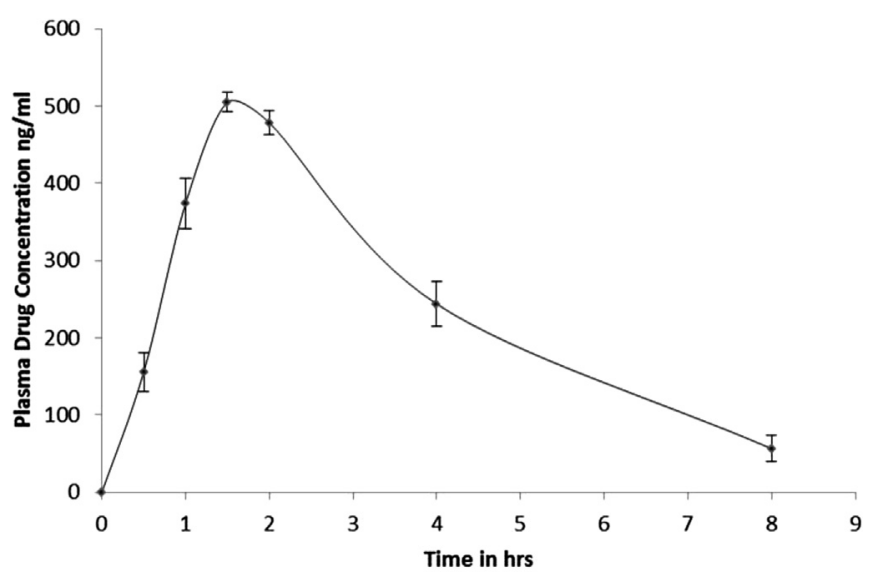

Fig. 6. Plasma concentration-time curve for conventional tablet.

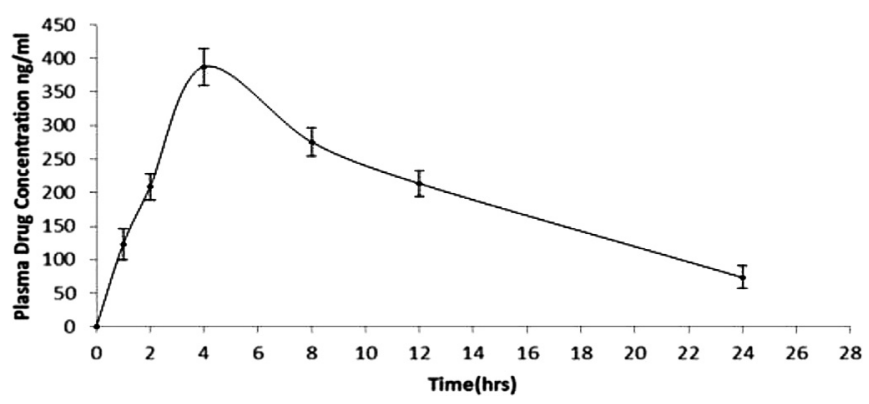

Fig. 7. Plasma concentration-time curve for extended release tablet.

Table 3

Pharmacokinetic parameters from the plasma concentration-time curve (results expressed are mean of six rabbits).

\begin{tabular}{lcc}
\hline Parameters & Conventional tablet & HA-2 \\
\hline$C_{\max }(\mathrm{ng} / \mathrm{ml})$ & $505.20 \pm 20.67$ & $403.75 \pm 28.77$ \\
$T_{\max }(\mathrm{h})$ & $1.5 \pm 0.0$ & $4.0 \pm 0.0$ \\
$\mathrm{AUC}_{0-\mathrm{t}}(\mathrm{ng} \mathrm{h} / \mathrm{ml})$ & $3039.1 \pm 215.98$ & $4895.2 \pm 314.66$ \\
$M R T(h)$ & $3.5 \pm 2.67$ & $14.3 \pm 3.59$ \\
Elimination rate & $0.3649 \pm 0.09$ & $0.08821 \pm 0.01$ \\
$\quad$ constantKe $\left(h^{-1}\right)$ & & \\
\hline
\end{tabular}

is high drug release rates are too low. Once there is sufficient polymer concentration in the matrix system a uniform barrier is formed. This barrier protects the drug from releasing immediately into the dissolution medium. Only formulation HA-2 followed the desired release profile up to $24 \mathrm{~h}$.

The matrix tablets underwent both swelling and erosion at the same time after placement in the dissolution media. It has been reported that constant release can be obtained in such type of matrices. ${ }^{14}$ Constant release in such situations occurs because the increase in diffusion path length due to swelling is compensated for by continuous erosion of the matrix. ${ }^{15}$

SEM further confirmed both diffusion and erosion mechanisms to be operative during drug release from the optimized formulation (HA-2). Initially, tablet matrix showed swelling with pore formation that is clearly visible from SEM image. At the end of $12 \mathrm{~h}$, the matrix was intact and pores had formed through it. SEM images also show the formation of gel structure indicating swelling and pore formation on the tablet surface.

In case of Peppas model ${ }^{16} ; n$ values close to 0.64 indicate diffusion as the mode of release. In case of Higuchi $R^{2}$, the value was close to unity indicating a linear response and clearly supporting the Peppas model. HA-2 showed $\mathrm{R}^{2}$ value close to unity when zero order model was applied which indicates good linearity and hence following zero order release. Korsmeyer's plot showed good linearity with regression value of 0.9914 and slope 0.6562 indicating that diffusion is the dominant mechanism of drug release coupled with erosion. ${ }^{17}$

In case of conventional tablet, nateglinide was detectable in blood within 30 min after its oral administration in rabbits. The absorption was rapid with conventional tablets as indicated by low $t_{\max }$ value $(1.5 \mathrm{~h})$ in comparison with $\mathrm{HA}-2$ formulation which exhibited delayed absorption as demonstrated by high $t_{\max }(4 \mathrm{~h})$ values. $C_{\max }$ value of conventional tablet was high compared with HA-2 (Table 3). In comparison, HA-2 formulation exhibited low elimination rate constant and high values of mean residential time (MRT). The low area under the curve (AUC) was observed with conventional tablets whereas the extended release formulation showed high AUC values indicating increased bioavailability of the drug in the matrix tablet.

The results of the in vivo bioavailability test indicate that drug release from matrix tablet is controlled thereby providing prolonged drug delivery.

\section{Conclusion}

Extended release matrix tablets of nateglinide were prepared by direct compression. Various polymers in varying concentrations 
were developed and evaluated. The formulation containing 15\% HPMC K15M (HA-2) followed the desired release profile and was therefore selected for further studies. SEM studies revealed initial swelling and intact structure of the formulated tablets. Erosion and diffusion mechanisms were responsible for the sustained release of nateglinide from formulated matrix tablet. In vivo pharmacokinetic studies in rabbits confirmed the prolonged release by showing increase in bioavailability for matrix tablet compared to conventional tablet. The formulation (HA-2) was found stable under accelerated conditions for 3 months with respect to physical characteristics and drug content. However clinical studies and extensive stability studies at different conditions are required to confirm these results.

\section{Conflicts of interest}

All authors have none to declare.

\section{Acknowledgements}

The authors acknowledge the support of Manipal University in carrying out the research work.

\section{References}

1. Campbell IW. Nateglinide - current and future role in the treatment of patients with type-2 diabetes mellitus. Int J Clin Pract. 2005;59:1218-1228.

2. Basu SK, Rajendran A. Studies in the development of nateglinide loaded calcium alginate and chitosan coated calcium alginate beads. Chem Pharm Bull. 2008;56:1077-1084.
3. Mackino C, Ninomoya H, Okano A, Yabuki A. Design of nateglinide controlled release tablet containing erosion matrix tablet and multiple administration study in normal beagle dogs. Chem Pharm Bull. 2009;57:907-913.

4. Tentolouris N, Voulgari C, Katsilambros N. A review of nateglinide in the management of patients with type 2 diabetes. Vasc Health Risk Manag. 2007;3: 797-807.

5. Gupta PK, Robinson JR. Oral Controlled - Release Delivery. In: Kydonieus A, ed Treatise on Controlled Drug Delivery. 1st ed. New Jersey: Marcel Dekker; 1992 P255-P310.

6. Patel DM, Patel BK, Patel HA, Patel CN. Design of controlled release nonerodible polymeric matrix tablet using microwave oven-assisted sintering technique. J Young Pharm. 2011;3:176-180.

7. Jishnu V, Prabhakaran R, Gilhotra RM. Formulation and evaluation of cephalexin extended release matrix tablets using $3^{2}$ factorial design. J Young Pharm. 2011;3:259-266.

8. Gosh MN. Fundamentals of Experimental Pharmacology. 3rd ed. Kolkata, India: Hilton \& Company; 2005.

9. Paget GE, Barnes JM. Evaluation of drug activities. In: Laurence DR, Bacharach AL, eds. Pharmacometrics. 1st ed. New York, London: Academic Press; 1964.

10. Indian Pharmacopoeia. 5th ed. New Delhi: The Controller of Publications: 2007. Indian Pharmacopoeia, Government of India, Ministry of Health and Family and Welfare.

11. Al-Taani BM, Tashtoush BM. Effect of microenvironment pH of swellable and erodable buffered matrices on the release characteristics of diclofenac sodium. AAPS PharmSciTech. 2003;4:E43.

12. Parasuraman S, Raveendran R, Kesavan R. Blood sample collection in small laboratory animals. J Pharmacol Pharmacother. 2010;1:87-93.

13. Sankalia JM, Sankalia MG, Sutariya VB, Mashuru RC. Nateglinide quantification in rabbit plasma by HPLC: optimization and application to pharmacokinetic study. J Pharm Biomed Anal. 2007;44:196-204.

14. Efentakis M, Vlachou M, Naseef H. Swelling properties of various polymers used in controlled release systems. J Biomater Appl. 2001;16:125-138.

15. Mockel JE, Lippold BC. Zero-order release from hydrocolloid matrices. Pharm Res, 1993:10:1066-1070.

16. Ritger PL, Peppas NA. A simple equation for description of solute release: Fickian and non-Fickian release from nonswellable devices in the form of slabs spheres, cylinders or discs. J Control Release. 1992:5:23-36.

17. Korsmeyer RW, Gurny R, Peppas NA. Mechanism of solute release from porous hydrophilic polymers. Int J Pharmaceutics. 1993;15:25-35. 